\title{
Profesionalisme Guru Madrasah: Internalisasi Nilai Islam dalam Mengembangkan Akhlak Aktual Siswa
}

\author{
Syahraini Tambak*, Mawardi Ahmad, Desi Sukenti, Abd. Rahman bin Abd. Ghani \\ Unviersitas Islam Riau, Indonesia*, Unviersitas Islam Riau, Indonesia, Unviersitas Islam \\ Riau, Indonesia, Sultan Idris Education Unviersity, Malaysia \\ *Jl. Khaharuddin Nasution No. 113, Perhentian Marpoyan, Kota Pekanbaru \\ *Email: syahraini_tambak@fis.uir.ac.id
}

\begin{abstract}
Research on morals has been done a lot, but the internalization of Islamic values in its development is still not being found. This study aims to explore efforts of madrasah teachers to internalize Islamic values in developing students' actual morals. Using case study research and in-depth interviews with 12 madrasah tsanawiyah teachers, and analyzing them with qualitative analysis. This research resulted; Dhuha and fardhu prayer to manage syahwiya power, developing iffah, jud, syakha', qana'ah, amanah, zuhud, rahmah, hilm, and al-afwu; Shiyam sunnah, and tahfiz al-Qur'an to curb hammiya power, develop syaja'ah,' 'adalah, ihsan, insyaf, rahmah, and hilm; Muhadharah, and internalization of Islamic values in learning, to educate powers of mufakkara, developing wisdom and fathanah. In conclusion, dhuha and fardhu prayer, shiyam sunnah, tahfiz al-Qur'an, muhadharah, and internalization of Islam in learning, develop iffah, jud, syakha', qana'ah, amanah, zuhud, rahmah, hilm, al-afwu, syaja'ah, 'adalah, ihsan, insyaf, mujahadah, sabr, wisdom and fathanah. The results of this study have implications for the theory of teacher efforts to internalize moral development in madrasah.
\end{abstract}

Keywords: actual morals, Islamic values, internalization, professional teachers, madrasas

Abstrak: Penelitian tentang akhlak telah banyak dilakukan, namun internalisasi nilai Islam dalam pengembangannya masih belum ditemukan. Penelitian ini bertujuan mengeksplor upaya guru madrasah menginternalisasi nilai-nilai Islam dalam mengembangkan akhlak aktual siswa. Menggunakan penelitian studi kasus, dan wawancara mendalam pada 12 guru madrasah tsanawiyah, serta menganalisisnya dengan analisis kualitatif. Penelitian menghasilkan; Shalat dhuha dan fardhu berjamaah untuk mengelola jiwa syahwiya mengembangkan 'iffah, jud, syakha', qana'ah, amanah, zuhud, rahmah, hilm, dan al-afwu; Shiyam sunnah dan tahfiz al-Qur'an untuk mengekang jiwa hammiya mengembangkan syaja'ah, 'adalah, ihsan, insyaf, rahmah, dan hilm; Muhadharah dan internalisasi Islam dalam pembelajaran, mendidik jiwa mufakkara, mengembangkan hikmah dan fathanah. Simpulannya, shalat dhuha, shalat fardhu berjamaah, shiyam sunnah, tahfiz al-Qur'an, muhadharah, dan internalisasi Islam dalam pembelajaran, mengembangkan 'iffah, jud, syakha', qana'ah, amanah, zuhud, rahmah, hilm, al-afwu, syaja'ah, 'adalah, ihsan, insyaf, mujahadah, sabr, hikmah, fathanah, dan insyaf. Hasil penelitian ini berimplikasi pada teori upaya guru dalam internalisasi pengembangan akhlak di madrasah.

Kata Kunci: Akhlak Aktual, Nilai-nilai Islam, Internalisasi, Guru Profesional, Madrasah

Jurnal Pendidikan Agama Islam Al-Thariqah Vol. 5, No. 2, Juli - Desember 2020

Received: 12 September 2020; Accepted 17 December 2020; Published 20 December 2020

*Corresponding Author: syahraini_Tambak@fis.uir.ac.id 


\section{PENDAHULUAN}

Pengembangan akhlak aktual siswa sangat populer dalam pendidikan madrasah karena menjadi kunci sukses dalam kehidupan siswa kelak dalam kehidupan. Manusia yang memiliki akhlak aktual menjadi dasar bagi kesuksesan dalam profesi yang diemban. Bangunan literatur menunjukkan bahwa akhlak aktual siswa merupakan segala bentuk kebajikan yang diimplementasikan dari sifat-sifat Allah dalam kehidupan seharihari dan berdampak pada kesuksesan seseorang di masa depan (Tambak \& Sukenti, 2020). Akhlak merupakan perilaku baik seseorang menjadi dasar dalam bertindak yang menghantarkan manusia pada keberhasilan.

Penelitian ini meneliti tentang pengembangan akhlak aktual siswa. Sejauh ini, penelitian tentang pengembangan akhlak aktual sudah dilakukan riset para peniliti dari berbagai aspek dalam pendidikan Islam terkini. Penelitian Ganjvar (2019) di Isfahan, Iran, meneliti perilaku Islami siswa dengan memasukkan ajaran Islam dalam mengembangkannya dalam komunikasi dan kehidupan sebagai model pendidikan spiritual anak. Penelitian Rashid, Mohamed \& Azman (2017) di Malaysia, melihat bahwa perilaku Islami sangat urgen dikembangkan agar generasi bangsa terhindar dari perilaku cyberbulliying dalam kehidupan modern. Mamat, and Siti Fatahiyah Mahamood (2017) di Malaysia, meneliti tentang pengembangan sikap lingkungan didasarkan pada ajaran agama dan falsafah. Sebab perilaku masyarakat saat ini kurang memperhatikan akhlak terhadap lingkungan. Di samping itu juga penelitian Mohamed, Jasmi, \& Zailani (2016) pada berbagai guru di Malaysia bahwa akhlak menjadi bagian krusial yang harus dimiliki guru dalam membentuk pembelajaran yang berkesan. Penelitian Laeheem (2017) meneliti latar belakang keislaman pemuda Muslim
Thailand di tiga provinsi perbatasan selatan Thailand dalam hal asuhan, studi, menjalankan tugas agama, dan berpartisipasi dalam kegiatan. Akhlak menjadi persoalan utama dalam setiap perilaku yang dikembangkan. Vojdani and Barandagh (2018) di Turki, meneliti dasar-dasar kognitif, konteks sikap, dan menggambarkan keislaman pola perilaku untuk menghormati orang lain secara maksimal dalam masyarakat, yang tidak terbatas pada individu yang sukses, atau berbudi luhur.

Penelitian Mu'awanah (2018) di Semarang, Indonesia yang mengembangkan akhlak dalam pembelajaran dengan berbagai pendekatan. Maulida (2017) dalam penelitiannya memandang akhlak generasi bangsa memerlukan perbaikan sehingga diperlukan disain pendidikan akhlak untuk Islamisasi pribadi dan masyarakat. Ayu \& Junaidah (2018) di Bandar Lampung, meneliti pengembangan akhlak pada pendidikan anak usia dengan mengujicobakan konstruk akhlak sebagai langkah perbaikan dalam pembelajaran. Basuki \& Febriansyah (2020) di Bekasi meneliti pembentukan karakter Islami pada madrasah aliyah melalui pengembangan mata pelajaran akidah akhlak. Penelitian Zainuddin (2019) pada siswa madrasah ibtidaiyah dalam mengatasi akhlak siswa dengan mengembangkan bahan ajar bernilai akhlak. Karim (2017) meneliti pengembangan kepribadian Islam siswa madrasah tsanawiyah di Deli Serdang dengan penerapan pembelajaran akidah akhlak berbasis nilai-nilai Islami.

Berbagai penelitian tersebut mengarah pada pengembangan akhlak siswa dengan berbagai solusi yang ditawarkan, namun persoalan ini masih tetap saja terjadi pada siswa termasuk di Madrasah Tsanawiyah Negeri 2 Kota Pekanbaru, Riau, Indoensia. Ditemukan gejala di mana terdapat sebagian siswa pada madrasah ini, yang kurang baik 
dalam menerapkan perilaku baik di sekolah, kurang menghormati guru, termasuk orang tua, dan kurang menghargai teman, dan juga kurang bekerja keras dalam belajar. Sejatinya hal ini tidak terjadi pada diri siswa, sebab guru di madrasah telah senantiasa memberikan arahan, pengajaran, dan bimbingan untuk menerapkan akhlak aktual dalam setiap tindakan baik di madrasah dan masyarakat.

Maka, untuk menyelesaikan persoalan akhlak siswa ini diperlukan upaya guru madrasah, selain yang telah diteliti para peneliti sebelumnya, dengan menginternalisasi nilai-nilai Islam dalam mengembangkan akhlak aktual siswa di madrasah. Penelitian ini meneliti upaya guru madrasah menginternalisasi nilainilai Islam dalam mengembangkan akhlak aktual siswa Madrasah Tsanawiyah Negeri 2 Kota Pekanbaru. Riset ini merupakan penelitian terkini dan belum pernah diteliti peneiti lain di bidang pendidikan Islam. Pengembangan akhlak dilakukan dengan internalisasi nilai Islam berdasarkan pengelolaan, pengekangan, dan pengajaran daya jiwa manusia. Penelitian ini memfokuskan pada; internalisasi nilai-nilai Islam dalam mengekang daya jiwa syahwiya siswa sehingga menghasilkan akhlak aktual; internalisasi nilai-nilai Islam dalam mengelola daya jiwa hammiya siswa sehingga menghasilkan akhlak aktual; dan internalisasi nilai-nilai Islam dalam mendidik daya jiwa mufakkara siswa sehingga menghasilkan akhlak aktual. Dengan demikian akan ditemukan model internalisasi nilai-nilai Islam dalam mengembangkan akhlak aktual siswa madrasah.

\section{KONSEP TEORI}

Teori akhlak aktual dalam penelitian ini merujuk pada teori etika Islam Amril (2002) yang dalam penelitiannya mengembangkan teori Moral Raghib al-Isfahani, mengemukakan istilah akhlak aktual. Amril (2015) membagi akhlak itu ke dalam dua bagian yang dia istilahkan dengan akhlak potensial dan akhlak aktual. Akhlak potensial berbentuk khuluq (karakter) yang merupakan bentuk daya ghariziya yang dianugerahkan Sang Pencipta pada manusia untuk diaktualisasikan dalam bentuk perilaku. Akhlak potensial adalah penganugerahan sifat-sifat Ilahiah yang telah dianugerahkan Allah SWT baik dengan meniupkan ruh-Nya kepada manusia dengan menanamkan akhlaqi oleh Allah SWT melalui pengajaran langsung Allah SWT kepada Nabi Adam sebagai nenek moyang manusia ataupun melalui perjanjian primordial manusia dengan Allah SWT sebagai Dzat untuk disembah. Akhlak aktual berbentuk perilaku yang disumberkan pada jiwa manusia setelah dilakukan upaya secara berkesinambungan sehingga melahirkan perilaku bajik dalam kehidupan. Akhlak aktual merupakan pengimplementasian asma al-husna Allah SWT pada setiap perilaku manusia dalam aktivitas keseharian.

Dengan demikian perilaku akhlak aktual merupakan tindakan kebajikan berdasarkan asma al-husna Allah SWT yang diupayakan secara terus menerus sehingga menumbuhkembangkan perilaku bajik dalam kehidupan manusia. Hal ini dapat dipahami bahwa akhlak yang sesungguhnya adalah akhlak aktual karena ia mucul dari akhlak potensial setelah adanya usaha untuk mengaplikasikannya dalam tindakan nyata manusia. Akhlak potensial berisi sifat-sifat ilahiah yang harus diaplikasikan dalam tindakan kehidupan sehari-hari manusia. Akhlak sebagai perlaku kebajikan yang dihasilkan berdasarkan upaya manusia mengimplementasikan potensi asma alhusna dalam tindakan nyata kehidupan. Akhlak aktual adalah suatu perbuatan yang berbasis pada kejiwaan yang dikelola dari pengelolaan daya jiwa 
manusia dengan pembiasaan aktivitas asma al-husna secara kontiniu dan istiqomah sehingga melahirkan perilaku kebajikan dalam kehidupan masyarakat (Amril, 2015).

Akhlak aktual mengandung semua sifat yang terjalin dalam perilaku yang diridhai oleh Allah SWT sekaligus juga alQur'an dan Sunnah yang menjadi sumber utama bagi nilai perilaku akhlak itu sendiri. Akhlak aktual tidak dapat dipisahkan dengan sifat-sifat terpuji dan dihubungkan dengan sifat-sifat Allah SWT dalam setiap ragam perilaku manusia dalam aktivitas sehari-hari. Allah SWT berserta utusan, perintah-perintah dan segala yang diinginkan-Nya menjadi ukuran bagi perilaku akhlak (Amril, 2002).

Ibnu Miskawih (2011) dalam teori akhlaknya mengungkapkan dimana akhlak sebagai suatu perilaku kejiawaan manusia yang dilakukan secara terusmenerus secara spontan dalam bentuk perbuatan kebajikan. Akhlak merupakan aktivitas kejiwaan seseorang dimana melahirkan perbuatan-perbuatan kebajikan yang mudah dilaksanakan tanpa memerlukan pertimbangan (Tambak \& Sukenti, 2020). Chen and YunWen Chan (2020) mengungkapkan bahwa moral dapat dikembangkan dengan pembiasaan perilaku yang baik sehingga menjadi kebiasaan dan berdampak pada kesetaraan kenyamanan hidup manusia di muka bumi.

Menurut Amril (2002), untuk mengembangkan akhlak aktual, manusia harus terlebih dahulu menyucikan 3 (tiga) daya jiwa manusia, adalah daya jiwa mufakkara, daya jiwa syahwiya, dan daya jiwa hammiya manusia. Di sinilah proses internalisasi nilai-nilai Islam itu terjadi sehingga memunculkan perilaku akhlak aktual peserta didik. Daya hammiya dan daya syahwiyah harus dikekang karena tidak memiliki akses sampai kepada ilahiah serta mengembangkan daya mufakkara.
Mengekang daya hammiya dan daya syahwiya dan serta mengembangkan daya mufakkara inilah yang dapat menghasilkan akses sampai kepada Allah SWT dan inilah jalan untuk bisa menjadi khalifah. Proses penyucian daya jiwa mufakkara dapat dilakukan dengan aktivitas mendidiknya melalui pembelajaran, yang kemudian melahirkan perilaku hikmah dan 'ilmu. Penyucian daya jiwa syahwiya dilakukan dengan mengekangnya secara maksimal melalu makarim syariah, sehingga melahirkan perilaku iffah dan jud. Sementara itu penyucian daya jiwa hammiya dilakukan dengan memimpin daya ini sehingga tunduk pada akal, yang kemudian melahirkan perbuatan syaja'ah dan hilm. Apabila ketiga daya ini terkontrol bersih dan teraplikasikan dengan sempurna, maka akan melahirkan perilaku 'adalah (adil).

Menurut Raghib al-Isfahani (1987) dalam filsafat moralnya, mengatakan bahwa hikmah (bijaksana) bila kuat mampu memunculkan pola pikir tingkat tinggi (ilmu) dan kemampuan mengingat yang tinggi-fathanah (cerdas). Perilaku syaja'ah apabila diperkuat, maka capaian utama tertinggi melahirkan perilaku jud (murah hati), hilm (santun), mujahadah (patriot), dan sabar. 'Iffah (sederhana) jika kuat akan melahirkan perbuatan jud (murah hati), shakha' (dermawan), qana'ah (rela), amanah (jujur), wara' (salih), zuhud, rahma (ingin mengembalikan hak orang lain), dan hilm (santun). Demikian pula halnya dengan 'adalah jika kuat dapat melahirkan ihsan, insaf (proporsional), rahma (ingin mengembalikan hak orang lain), hilm (santun), dan 'afwu (pemaaf).

Ibnu Miskawaih (2011) membagi akhlak menjadi lima perilaku kebajikan yaitu, hikmah (kebijaksanaan), 'iffah (sederhana), syaja'ah (berani), sakha' (dermawan), dan 'adalah (adil). Kebijaksanaan merupakan kepandaian, ingatan kuat, berpikir tingkat tinggi, pemahaman yang cepat dan kebenaran 
argumentasi, pemikiran yang jernih, dan memiliki kemampuan mempelajari sesuatu dengan mudah. Sederhana merupakan perilaku malu, tenang, sabar, berwibawa, wara' dan lainnya. Berani merupakan kepemilikan kebesaran jiwa, keuletan, ketegaran jiwa, ketenangan, ketabahan, penguasaan diri, keperkasaan, serta keuletan pada pekerjaan. Kedermawanan merupakan kemurahan jiwa, mendahulukan kepentingan manusia, kerelaan, bakti diri, serta keterbukaan tangan. Perilaku keadilan merupakan persahabatan diri, kebersemangatan sosialis, bersilaturahim, kemampuan keterlimbalan, kooperatif yang bijaksana, pandai dalam mengambil keputusan sebuah persoalan, memiliki mahabbah, dan kemampuan ibadah yang tinggi.

Maka, proses internalisasi nilai-nilai Islam dalam mengembangkan akhlak aktual siswa dapat dikembangkan dengan menyucikan ketiga daya jiwa manusia, yaitu daya jiwa mufakkara, daya jiwa syahwiya, dan daya jiwa hammiya. Daya hammiya dan daya syahwiyah harus dikekang dengan penerapan nilai-nilai Islam karena tidak memiliki akses sampai kepada Ilahiah serta mengembangkan daya mufakkara. Penyucian daya jiwa mufakkara dilakukan dengan mendidiknya melalui belajar tentang nilai-nilai Islam, sehingga dapat melahirkan hikmah dan 'ilmu; Penyujian daya jiwa syahwiya dengan cara mengekangnya dengan internalisasi nilainilai Islam, sehingga dapat melahirkan iffah dan jud; Sementara menyucikan daya jiwa hammiya dilakukan dengan memimpin daya ini melalui internalisasi nilai-nilai Islam, sehingga tunduk kepada akal, selanjutnya akan melahirkan syaja'ah dan hilm.

\section{METODE PENELITIAN}

Penelitian kualitatif dengan menggunakan pendekatan studi kasus (Strauss and Corbin, 1990) merupakan jenis penelitian yang ditetapkan, yang bertujuan untuk mengeksplor upaya guru menginternalisasi nilai-nilai Islam dalam mengembangkan akhlak aktual siswa berdasarkan kumpulan berbagai data lapangan dari guru madrasah. Proses pelaksanaan penelitian ini dilaksanakan pada Madrasah Tsanawiyah (MTs) Negeri 2 Kota Pekanbaru, dan berlangsung selama 2 (dua) tahun, dan melibatkan 12 guru madrasah yang merupakan tujuh perempuan dan lima orang guru laki-laki.

Wawancara mendalam dijadikan sebagai teknik pengumpulan data dalam proses penelitian. Setiap guru madrasah berpartisipasi dalam tiga rangkaian wawancara dengan peneliti. Setiap wawancara berlangsung hingga 2-3 jam. Rangkaian tiga wawancara ini mengikuti model Seidman (1991) yang berfokus pada eksplorasi pengalaman rinci, dan yang terakhir berfokus pada "refleksi pada makna". Wawancara pertama menggunakan metode naratif kehidupan dan meminta guru madrasah untuk merefleksikan "internalisasi nilai-nilai Islam dalam membentuk perilaku islami siswanya?" Wawancara kedua adalah untuk menggali pengalaman guru dan bagaimana mereka sebenarnya menerapkan internalisasi nilai-nilai Islam dalam mengembangkan akhlak aktual siswa dalam pembelajaran di madrasah. Wawancara ketiga mengeksplorasi bagaimana metode internalisasi nilai-nilai Islam yang dipergunakan guru dalam mengembangkan akhlak aktual siswa di lingkungan madrasah.

Analisis data dilakukan melalui beberapa tahapan yaitu pembersihan data, transkrip, pengkodean dan kategorisasi, serta interpretasi (Merriam 1998; Miles dan Huberman 1994; Patton 2002). Setiap malam setelah pengumpulan data, anggota tim saya dan saya membahas informasi yang kami temukan, kami identifikasi hasil wawancara yang sesuai dengan tujuan penelitian. Setelah data dibersihkan, kami membuat transkripsi verbatim dan menganalisisnya sesuai dengan kaedah 
Bahasa Indonesia yang berlaku. Kami melukan pengodean transkripnya, mengelompokkannya ke dalam tema, dan membandingkannya di seluruh fenomena. Tema yang paling sering muncul dari ketiga masalah tersebut antara lain; (a) internalisasi nilai Islam dalam mendidik kekuatan jiwa mufakkara; (b) internalisasi nilai-nilai Islam dalam menekan kekuatan jiwa hammiya sehingga malahirkan akhlak aktual siswa; (c) internalisasi nilai-nilai Islam dalam mengelola kekuatan jiwa syahwiya untuk melahirkan akhlak aktual siswa. Di bawah masing-masing tema ini, beberapa subtema diidentifikasi; beberapa di antaranya berbeda dari kasus ke kasus. Dengan langkah-langkah tersebut, saya berhasil menghasilkan preposisi teoritis dari data penginternalisasian nilai Islami pada proses pengembangan akhlak aktual peserta didik pada madrasah.

\section{HASIL DAN PEMBAHASAN}

\section{Internalisasi Nilai Islam dalam Mengelola Daya Jiwa Syahwiya}

Pembentukan

tingkah

laku

keislaman siswa diawali dengan memusatkan perhatian pada kekuatan jiwa dalam diri manusia yaitu kekuatan syahwiya atau biasa disebut nafsu. Nafsu duniawi adalah jiwa yang selalu mengedepankan keinginan materialistis dan menyembah dunia hedonistik tanpa batas. Kekuatan syahwiya harus ditekan dalam aktivitas kehidupan dengan; pembiasaan shalat sunnah dhuha, dan pelaksanaan shalat fardhu berjamaah. Kedua cara tersebut mampu menekan kekuatan jiwa syahwiya, yang pada gilirannya melahirkan sikap dan perbuatan kebajikan 'iffah. Penguatan keutamaan 'iffah dengan ketiga metode tersebut melahirkan jud, syaka', amanah, 'afwu, zuhud, rahmah, dan hilm. Kebajikan inilah yang membuat siswa menjadi individu yang saleh.

\section{Membiasakan shalat sunnah dhuha}

Proses internalisasi nilai Islami untuk mengembangkan akhlak aktual peserta didik pada MTs Negeri 2 Pekanbaru dilakukan melalui pembiasaan ibadah shalat dhuha. Proses melaksanakan kegiatan shalat dhuha ini erat kaitannya dengan misi madrasah yang telah ditetapkan sebelumnya sebagai madrasah unggul dalam pengembangan akhlak peserta didik. Semua guru di madrasah merasa bahwa penerapan pembiasaan sholat sunnah sangat penting untuk membentuk akhlak siswa dalam kehidupan sehari-hari. Pembiasaan sholat sunnah yang dilakukan di madrasah dimaksudkan untuk menekan kekuatan syahwiya atau nafsu duniawi. Hal itu dilakukan agar siswa sadar bahwa dengan shalat sunnah hidup akan disiplin, fokus dan bermakna. Sholat sunnah yang dilaksanakan, menurut seorang guru "menyadarkan siswa untuk terlepas dari belenggu dunia, seperti rutinitas yang mengikat, kebiasaan buruk, dan perbuatan lain yang terkadang sulit dilakukan, membebaskan diri dari ketakutan dan kemalasan karena glamor dunia dapat dilakukan dengan membiasakan shalat sunnah di sekolah. Dengan kebiasaan melakanakan shalat ini, para siswa terlihat lebih santun, disiplin, dan lainnya," (1).

Setiap pagi hari, kegiatan siswa diawali dengan sholat sunnah duha. Sholat sunnah ini wajib dilakukan oleh semua siswa tanpa terkecuali. Sholat ini juga dilakukan di masjid secara bersamasama, tetapi tidak berjamaah. Meski demikian, para guru terus memimpin di depan seperti seorang imam. Pelaksanaan sholat dhuha yang mengawali kegiatan belajar di pagi hari dimaksudkan agar siswa memiliki jiwa yang ikhlas, bersih, taat, religius, dan bermotivasi tinggi untuk mengikuti kegiatan belajar.

Dengan pelaksanaan shalat ini "maka kekuatan syahwiya ditekan secara signifikan sehingga melahirkan amalan- 
amalan luhur yaitu 'iffah (hidup sederhana). Keutamaan 'iffah ini melahirkan amal saleh lainnya. Tindakan tersebut tercermin dalam kehidupan sehari-hari siswa. Mereka menunjukkan sikap jud, shakha', qana'ah (rela), amanah (jujur), wara' (salih), zuhud, rahma (keinginan untuk memulihkan hak orang lain), dan hilm ( sopan)" (3).

Penelitian Sapitri

menemukan bahwa shalat dhuha yang dilakukan oleh peserta didik memiliki hubungan yang kuat dengan akhlak peserta didik. Dunia pendidikan Islam mempunyai banyak tujuan yang hendak dicapai, termasuk dalam menumbuhkan perilaku akhlak mulia pada peserta didik. Dengan pembiasaan shalat dhuha di sekolah maupun di luar sekolah seharusnya peserta didik mampu memahami dan dapat membangun akhlak yang mulia pada diri peserta didik masing-masing.

Penerapan nilai-nilai keislaman dalam menumbuhkembangkan akhlak peserta didik dengan melaksanakan shalat sunnah dhuha untuk mengekang daya jiwa syahwiya. Seorang guru madrasah mengungkapkan:

"Pelaksanaan shalat sunnah dhuha yang diterapkan di madrasah ini merupakan tradisi yang telah lama kami laksanakan. Shalat sunnah dhuha ini dilaksanakan secara rutin setiap pagi hari dan diikuti oleh semua siswa. Tujuannya agar peserta didik mengontrol jiwanya sehingga melahirkan perilaku sopan, kerja keras, wara', disiplin, dan jiwa yang tenang. Kami juga sangat senang mengikuti kegiatan ini karena kebersamaan yang dilakukan saat shalat sunnah dhuha merupakan teladan yang membuat peserta didik memiliki rasa hormat pada guru yang kami harapkan akan datang keberkahan. Mereka berkah menerima ilmu yang kami berikan, dan mereka pun kelak hidup berkah dengan ilmu yang didapatkan." (11).

Shalat dhuha yang dilakukan peserta didik merupakan proses pembentukan jiwa syahwiya agar mereka mampu mengontrol nafsu hedonistik dan mengembangkan pada nilai keislaman. Seorang guru Akidah Akhlak menuturkan bahwa "shalat dhuha berdampak luas pada diri siswa dalam bertindak, bertutur kata, merespon dan bersosialisasi dalam kehidupan madrasah maupun masyarakat," (9). Hal ini mengindikasikan shalat dhuha yang selama ini dilaksanakan mampu menghantarkan siswa mampu mengelola daya jiwa syahwiya sehingga membuahkan perilaku kebajikan dalam kehidupan keseharian.

Hasil penelitian Rosad (2020), menggambarkan bahwa pelaksanaan shalat dhuha bertujuan menamkan aspek kedisiplinan siswa, memanfaatkan waktu dengan baik, dan mengingat kepada Allah SWT. Dengan adanya pembiasaan yang positif seperti shalat dhuha di waktu yang telah ditetapkan dimungkinkan siswa berpegang teguh pada nilai-nilai Islami dan terhindar dari perilaku hedonistiksekuler. Siswa menyadari bahwa jiwa yang baik mesti mengontrolnya dengan pelaksanaan shalat sunnah dhuha dalam kehidupan belajar.

Temuan penelitian ini juga diperkuat oleh hasil penelitian Warasto (2018) bahwa pembiasaan shalat dhuha mampu mengembangkan perilaku kebajikan dalam aktivitas pembelajaran dan kehidupan sosial, seperti akhlak pada diri sendiri, orangtua, masyarakat, dan lingkungan. Zuhdi (2019) dalam temuan penelitiannya mengungkap bahwa pembiasaan shalat dhuha berdampak pada munculnya perilaku jud, shakha', qana'ah, amanah dan hilm. Hasil penelitian Ayunda (2019) menguatkan temuan penelitian ini yang menyatakan bahwa pembiasaan shalat sunnah dhuha mampu melahirkan perilaku kebaikan dan hal ini menjadi fondasi dalam 
kehidupan siswa untuk berprestasi dan sukses. Temuan penelitian Laila (2020) membuktikan secara kerolasional bahwa pelaksanaan shalat dhuha berdampak 25.7\% pada pembentukan akhlak peserta didik.

Penelitian Amri (2018) juga mengungkapkan bahwa program kegiatan shalat dhuha melahirkan perilaku makarim syari'ah dalam kehidupan siswa. Para siswa lebih mempergunakan waktu untuk membaca, tekun dalam belajar, disiplin dalam belajar, menghormati orangtua, memiliki kesantunan yang bertambah, dan sikap sosial yang tinggi.

Temuan peneliti lainnya yang dikemukakan oleh Firdaus (2019) memperkuat hasil penelitian ini bahwa pengamalan shalat sunnah dhuha melahirkan siswa unggul dan kompetatif (ulil albab) yang memadukan kecerdasan intelektual, kecerdasan emosional dan spiritual. Di samping itu ditemukan juga penelitian Nurani (2019) yang menguatkan temuan penelitian ini mengungkapkan bahwa pembiasaan sholat sunnah dhuha pada peserta didik sangat efektif dan berpengaruh pada terbentuknya peserta didik yang berakhlak terpuji, yaitu dermawan, mencintai sesama, dan jujur.

\section{Pelaksanaan shalat fardhu berjama'ah}

Mengembangkan perilaku Islami siswa di madrasah ini dilaksanakan dengan mendirikan shalat fardhu secara berjamaah. Hal ini dirasakan penting, madrasah di samping sebagai sekolah Islam, memang harus mampu mengembangkan tradisi pengembangan keimanan siswa. Pelaksanaan shalat fardhu berjamaah di madrasah berlanjut dalam kehidupan masyarakat kesehariannya di rumah sehingga mengekang jiwa syahwiya siswa yang kemudian melahirkan akhlak baik dalam kehidupan mereka.
Shalat fardhu dzuhur dan ashar berjamah dilakukan sebagai kebijakan madrasah yang mesti dijalankan oleh semua siswa dan semua guru. Wakil kepala madrasah bidang kurikulum, menyatakan "program aktivias shalat fardhu dzuhar dan ashar dilaksanakan berlangsung sejak 10 tahun yang lalu. Tujuannya untuk membiasakan siswa mencintai Islam sekaligus pengembangan jiwa muthmainnah mereka agar rajin belajar, mencintai ilmu pengetahuan, dan terlepas dari belenggu hedonistik."

Pelaksanaan shalat fardhu berjamaah, baik dhuhur dan ashar, "dilakukan dengan dipimpin oleh imam shalat yaitu guru dan dibantu oleh peserta didik yang mampu. Pelaksanaan shalat zuhur dan shalat ashar berjamaah di madrasah diikuti oleh peserta didik, baik laki-laki maupun perempuan. Disebabkan keterbatasan tempat, lakilaki di masjid sementara perempuan di ruang kelas" (5). Pelaksanaan shalat fardhu berjamaah ini memiki aturan, seperti halnya yang disampaikan oleh seorang guru, bahwa "kebijakan madrasah memberikan aturan dalam pelaksanaan shalat fardhu berjamaah dan memberikan sanksi bagi siswa yang tidak melaksanaan." (5).

Pelaksanaan shalat zuhur dan ashar berjamaah mendapat pengawasan ketat dari guru. Pengawasan ini dimaksudkan agar pelaksanaan shalat berjamaah dapat berjalan dengan tertib. Seorang guru Fiqh mengatakan:

"Guru wali kelas dibantu oleh 2 orang siswa perkelas mengawasi proses pelaksanaan shalat. Mulai dari berwudhu sampai di masjid atau di kelas masing-masing. Seluruh siswa ketika telah memasuki waktu shalat diarahkan secara bersama-sama untuk melaksanakannya." (6).

Tujuan pembinaan pelaksanaan shalat fardhu berjamaah adalah "agar siswa memiliki sikap sosial, kecerdasan prososial, saling menghormati, jujur, dan 
disiplin. Di samping itu juga adalah menguatkan keimanan dan ketakwaan mereka sehingga mudah diatur, kerja keras dalam belajar, serta memiliki kepekaan sosial" (3). Tujuan lainnya yang lebih krusial menurut seorang guru adalah:

"dengan shalat fardhu berjamaah yang dilakukan diharapkan semua siswa dapat mengontrol nafsu keduniaannya sehingga muncul akhlak sederhana, dermawan, jujur, serta sikap bajik lainnya dalam kehidupan. Tujuan belajar mereka bukan sekedar untuk dunia tapi juga untuk mencapai kedekatan kepada Allah SWT dan mengusai ilmu Allah yang sangat luas. Jika shalat berjamaah telah dibiasakan, maka iman meningkat" (4).

Temuan penelitian ini diperkuat oleh riset Ikhsan (2017) yang mengungkap bahwa pembinaan pelaksanaan shalat fardhu berjamaah bertujuan agar mereka terbiasa disiplin dan mencintai sesama. Dengan pembiasaan shalat fardhu berjamaah maka peserta didik mengalami perubahan perilaku ke arah kebaikan yang dirasakan secara universal. Penelitian Avivah (2020) mengungkap bahwa shalat fardhu berjamaah berpengaruh terhadap spiritual quotient siswa dalam kehidupan. Kemampuan siswa dalam mengembangkan perilaku keislaman dalam menyelesaikan persoalan hidup dapat meningkat secara signifikan.

Di samping itu penelitian yang dilakukan oleh Saani (2017) menguatkan penelitian ini yang menyatakan bahwa shalat fardhu dzuhur dan ashar berjamaah yang dibiasakan memiliki hubungan sigifikan dengan peningkatan pencegahan kenakalan santri. Penelitian Ningsih (2017) juga menguatkan hasil temuan ini bahwa perilaku keagamaan dapat ditumbuhkembangkan secara maksimal dengan pelaksanaan shalat fardhu berjamaah yang dibiasakan dalam kehidupan sehari-hari. Penelitian Karjanto (2018) yang menyatakan bahwa pembiasaan sholat fardhu berjamaah memiliki hubungan signifikan dalam membentuk akhlak kedisiplinan siswa dalam belajar. Temuan penelitian Budianto (2020) juga menyatakan shalat fardhu berjamaah yang intens dilakukan berkorelasi kuat dengan perilaku kedisiplinan siswa sebagai perwujudan diri sholeh.

\section{Internalisasi Nilai Islam dalam Mengelola Daya Jiwa Hammiya}

Pembentukan perilaku Islami siswa dimulai dengan memperhatikan kekuatan jiwa pada diri manusia yaitu kekuatan hammiya atau disebut gejolak amarah. Gejolak amarah memiliki kekuatan untuk selalu menampilkan amarah dan sangat berpengaruh pada sikap seseorang. Kekuasaan hammiya dapat dikendalikan, seperti yang dilaksanakan di madrasah ini, dengan shiyam sunnah, dan tahfiz alQur'an. Penggunaan kedua pembiasaan tersebut mampu mengontrol kekuatan hammiya yang melahirkan perilaku syaja'ah. Tingkah laku syaja'ah melahirkan amalan-amalan baik linnya yaitu jud, hilm, mujahadah, dan sabr.

\section{Pembiasaan shiyam sunnah}

Kebijakan di MTs Negeri 2 Kota Pekanbaru mewajibkan seluruh siswanya membiasakan shiyam sunnah pada setiap hari Senin dan hari Kamis. Pelaksanana puasa sunnah ini bertujuan untuk mengelola mental peserta didik sehingga mereka memiliki sifat kelembutan, mudah diatur dalam belajar, mencintai belajar, percaya pada diri sendiri, dan keimanan yang baik. Di samping itu untuk mengembangkan perilaku yang berbudi luhur agar siswa terhindar dari penguasaan amarah, belenggu keburukan jiwa sehingga melahirkan perilaku syaja'ah (berani) dan sabar" (3).

Madrasah membuat aturan di mana pada siang hari madrasah tidak 
memperbolehkan makan siang dan kantin pun ditutup. Sore harinya pihak madrasah menyediakan ta'zil kepada siswanya yang ingin berbuka puasa di madrasah. Namun juga diberikan kebebasan bagi siswa untuk berpuka puasa di rumah. Kegiatan ini dilakukan secara rutin untuk menumbuhkan kesadaran kepada mahasiswa sekaligus mendekatkan diri kepada Allah SWT. Seorang siswa menyatakan, "pada awalnya, saya kesulitan mengikuti rutinitas ini, tapi perlahan-lahan saya beradaptasi, dan akhirnya saya bisa menahan emosi" (7). Pengakuan seorang guru mengungkapkan bahwa, "dengan penerapan metode shiyam, siswa lebih mudah diatur, menghormati guru, lebih sabar, dan mampu menguasai emosi" (8).

Puasa sunnah memiliki berbagai dampak yang ditimbulkan pada perilaku siswa dalam bersikap sosial (beradabtasi) dengan orang-orang yang berada di lingkungan madrasah. "Kemampuan sosial siswa yang berpuasa meningkat selama mereka sedang berpuasa. Mereka memiliki peningkatan kemampuan untuk berinteraksi dengan baik antar sesama, memiliki tingkat kesadaran yang tinggi dalam mengelola emosi diri dan orang lain" (7).

Hasil penelitian ini dikuatkan oleh temuan penelitian Maghfuroh (2019) bahwa pelaksanaan pembiasaan puasa sunnah di sekolah mampu membentuk perilaku kebajikan dimana siswa merasa butuh dengan Allah sehingga mereka merindukannya, tumbuh kesadaran dalam menjalankan agama, dan gemar melaksanakan kebaikan. Asyifa (2019) dalam penelitiannya mengungkapkan bahwa pembiasaan berpuasa sunnah di kalangan seperti puasa sunnah Senin Kamis dan Ayyamul Bidh, dan kegiatan keteladanan seperti puasa sunnah arafah dan tarwiyah, berdampak pada tumbuhnya jiwa religious siswa yaitu disiplin, sabar, syukur, tawakal, ridha, dan mujahadah.
Temuan penelitian ini juga dikuatkan oleh hasil penelitian Haibah, Mujahidatul, et. al. (2020) dimana pembiasaan berpuasa sunnah memberikan hikmah yang baik dan positif kepada kecerdasan emosional siswa yang rutin menjalankannya. Dengan puasa sunnah ini, perilaku siswa tumbuh dengan kebiasaan perilaku meliputi; (1) pengenalan diri sendiri, (2) pengendalian emosi diri, (3) peningkatan motivasi diri, (4) perkembangan sikap empati diri dan (5) perkembangan sikap sosial diri. Pembiasaan puasa sunnah dapat mengembangkan perilaku-perilaku kebajikan lain pada peserta didik. Hal ini karena puasa sunnah dapat menekan nafsu peserta didik (Ibrahim, Sarbini, \& Maulida, 2019; Hartini, 2015; Tambak, 2019). Temuan penelitian Husna (2016) juga menghasilkan bahwa puasa sunnah Senin dan Kamis mampu mengembangkan perilaku kebaikan siswa yang menuntunnya pada kesuksesan.

\section{Tahfiz al-Qur'an}

Menghafal al-Quran mengandung keutamaan tersendiri. Di setiap hurufnya terkandung sepuluh kebaikan bagi orang membacanya. Keutamaan lebih besar didapat mereka yang bisa menghafal alQuran. Salah satunya, jaminan masuk surga dan mahkota bagi orangtua. Maka, manajemen madrasah mengaggap bahwa tahfiz Qur'an sangat relevan diterapkan untuk membentuk siswa yang menjadi kebanggaan orangtua dan negara.

Program tahfiz Qur'an terapkan di madrasah dengan mewajibkan pada semua siswa untuk menghafal al-Qur'an 2 juz selama berada di madrasah. Untuk mensukseskan program ini, maka madrasah membuat jadwal khusus satu kali salam seminggu, di samping kebijakan wali kelas yang diterapkan di kelas masing-masing setiap hari. Prosesnya ada siswa melakukan setoran hafalan dan wali kelas menjadi penyimak 
untuk hafalan siswa. Hal ini dilaksanakan secara bergiliran pada semua siswa.

Strategi yang digunakan dalam proses menghafal al-Qur"an dengan metode talaqqi. "Metode talaqqi dilaksanakan melalui pendekatan $5 \mathrm{M}$ yaitu menerangkan, mencontohkan, menirukan, menyimak dan mengevaluasi" (7). Metode talaqqi adalah cara yang digunakan dalam mengajarkan tahfidz Qur'an dimana guru dan murid berhadapan langsung. Hal ini dilakukan untuk menghindari kekeliruan dan kesalahan dalam mengucapkan hurufhuruf al-Qur'an. "Dengan cara talaqqi, guru dapat menjelaskan bagaimana cara mengucapkan makhroj atau tempat keluarnya huruf, kemudian mencontohkan bunyi huruf sehingga siswa dapat langsung menirukan hurufhuruf atau ayat-ayat al-Qur"an yang dibacakan serta dapat dilakukan berulang-ulang sampai hafalan tersebut tersimpan di dalam memori ingatan anak" (6).

Tahfiz Qur'an ini diprogramkan bertujuan untuk mengekang daya hammiya siswa sehingga muncul perilaku bajik dalam kehidupan mereka. Seorang guru mengungkapkan: "program tahfiz Qur'an ini merupakan kegiatan penting di madrasah kami. Tujuannya adalah agar siswa mengembangkan perilaku mengenali diri dan mencintai al-Qur'an sehingga mereka mampu mengendalikan diri dengan ketenangan jiwa" (8).

Dengan membiasakan peserta didik menghafal al-Qur'an dalam pandangan Md, Ak Mohd Aiman Pg Hj (2020) maka akan muncul perilaku kebajikan baru pada diri peserta didik. Proses internalisasi yang dilakukan oleh guru dalam setiap pembelajaran tahfiz alQur'an di lingkungan madrasah membuat peserta didik marasakan kedamaian dan kenyamanan dalam kehidupan. Peserta didik semakin mudah menerima pelajaran yang disampaikan oleh para guru di madrasah. Mereka mudah diarahkan dalam proses mencapai target pembelajaran maupun kegiatan pengembangan akademik lainnya di madrasah.

\section{Internalisasi Nilai Islam dalam Memupuk Daya Mufakkara Melahirkan Akhlak}

Memupuk kekuatan jiwa mufakkara sebagai kekuatan berpikir yang mampu melahirkan perilaku mencintai ilmu dan fathanah diperlukan pembiasaan dengan pendidikan. Kekuatan ini menjadi elemen krusial karena mampu melahirkan peradaban yang mulia. Kekuatan mufakkara harus dipupuk dalam aktivitas kehidupan dengan pendidikan yang maksimal. Pengembangan dilakukan dengan pelaksanaan muhadharah, dan integrasi nilai Islam dalam pembelajaran. Tujuannya untuk membentuk perilaku kebijaksanaan, yang kemudian melahirkan tindakan mencintai ilmu dan fathanah.

\section{Melakasanakan muhadharah}

Muhadharah merupakan kegiatan rutin dilaksanakan setiap satu minggu sekali yang diikuti oleh peserta didik. "Kegiatan muhadharah diaksanakan setiap hari Jum'at pagi sebagai latihan para siswa agar memiliki keterampilan menganalisis dan mengkomunikasikan pemikiran. Kegiatan muhadharah ini dimaksudkan sebagai sarana bekal da'wah Islamiyah peserta didik di masyarakat nanti. Muhadharah merupakan salah satu kegiatan yang cukup efektif untuk melatih karakter keberanian dan ketrampilan siswa. Berani berbicara di depan orang banyak (temen-temennya), dan juga diawasi oleh oleh beberapa ustadz yang ditugaskan sebagai pembimbing kegiatan muhadharah ini" (3).

Siswa yang memiliki ketrampilan muhadharah dengan baik, maka menjadi modal awal baginya untuk terjun ke masyarakat, dan sebagai bentuk 
pembiasaan internalisasi nilai-nilai akhlak pada diri peserta didik. "Apabila keberanian dan kemampuan ini dikembangkan dengan baik, maka tidak menutup kemungkinan dia akan menjadi seorang orator yang hebat, yang bisa menempatkan dirinya di hadapan masyarakat pendengar yang beraneka ragam. Di samping membiasakan mereka memiliki akhlak menyampaikan kebaikan pada masyarakat" (3). bahwa:

Seorang guru mengungkapkan

"Di Madrasah kami, kegiatan muhadharah merupakan kegiatan rutin dilaksanakan setiap hari Jumat, dengan program pelatihan moderator, trainer, khotib jum'at, dan beragam jenis sambutan dikembangkan dengan pertimbangan paradigma dimasyarakat yang menuntut peserta didik bisa lebih cepat tanggap dan berbaur manakala berinteraksi dengan individu lain yang ada dalam kelompok sosialnya. Selain itu seorang peserta didik biasanya akan mendapatkan kepercayaan dari masyarakat sekitarnya untuk menjadi ketua/pemimpin dalam beragai macam kegiatan" (2).

Kegiatan muhadhoroh di madrasah ini, diawali dari paradigma "sampaikanlah dariku meskipun hanya satu ayat." Demikian Hadis riwayat Bukhari yang menjadi motivasi muslim untuk berdakwah. Dalam praktiknya, penyampaian ajaran Islam selain dengan tulisan juga harus dengan lisan. Sebagaimana metode dakwah lainnya, pidato juga menuntut kemampuan khusus. Seorang dai, khatib mupun orator harus menguasai berbagai teknik dan materi yang disampaikannya. Selain itu, mental pun sudah harus terlatih dan teruji untuk bisa dan berani berbicara di hadapan orang banyak.Meskipun materi telah matang dikuasai, tanpa mental yang terlatih penyampaian materi tersebut bisa kacau dan jauh dari harapan.
Menyadari bahwa madrasah sebagai lembaga pendidikan Islam yang mempersiapkan siswa dan siswi untuk berjuang dan menyebar ajaran Islam lewat berbagai metode juga tak lupa membekali siswa dan siswi dengan kemampuan pidato. Kegiatan muhadharah ini memiliki manfaat bagi perkembangan akhlak peserta didik di madrasah. Seorang guru mengungkapkan bahwa:

"Kegiatan muhadharah ini bertujuan untuk membekali siswa berbagai keerampilan. Pendidikan karakter merupakan salah satu konsep matra afektif dan menjadi sasaran utama kegiatan pendidikan di madrasah. Pengembangan karakter siswa ditempuh melalui berbagai kegiatan pembinaan kesiswaan. Salah satu bentuk program kegiatan kesiswaan adalah muhadharah (latihan berpidato)" (9).

Temuan penelitian ini diperkuat oleh penelitian Khoirum (2019) bahwa kegiatan muhadharah mampu mengembangkan kemampuan berpikir siswa sekaligus memiliki proses komunikasi yang baik di tengah masyarakat. Penelitian Sulistiawati (2017) menemukan bahwa siswa yang berpidato diberi kebebasan untuk menentukan tema yang akan disampaikan. Tujuannya adalah agar siswa lancar dalam membaca materi yang ada di naskah pidato tersebut. Latihan yang dilakukan siswa adalah dengan berlatih sendiri dan ada juga yang berlatih dengan teman sekelasnya berdampak pada kemampuan berpikir, analisis, pamahaman, dan retorika penyampaian yang lebih baik. Kegiatan ini berdamppak pada kemampuan analisis dan paradigma berpikir siswa. Penelitian Zahara (2020) mengungkap bahwa kegiatan muhadharah ini sangat penting bagi seluruh siswa.

Penelitian Kurnia (2018) juga menguatkan hasil penelitian ini bahwa 
strategi sasaran pelatihan muhadharah yang dilakukan dengan melatih mental santri agar mereka memiliki keberanian untuk berbicara di depan publik, mengembangkan minat dan bakat para santri, membentuk kader-kader da'i yang berkualitas, dan mengembangkan karakter berpikir yang berkualitas. Penelitian Dian (2018) menemukan bahwa melalui kegiatan ekstrakurikuler muhadharah sangat membantu meningkatkan percaya diri siswa dan keberanian siswa. Siswa yang semula takut, peragu, lemah menjadi berani, semangat, berfikir positif. Siswa yang semula hanya berani berbicara di belakang sekarang berani berpidato di depan teman-teman dan bapak ibu guru.

\section{Integrasi nilai Islam dalam pembelajaran}

Pengembangan daya jiwa mufakkara siswa dilakukan dengan mengajarkan nilai-nilai Islam dalam pembelajaran di madrasah dilakukan secara intensif. Integrsi nilai-nilai Islam ini diterapkan pada semua mata pelajaran yang ada di madrasah. Hal ini dilakukan dalam rangka pengembangan pola pikir siswa secara Islami sehingga melahirkan karakter hikmah dan fathanah.

Nilai-nilai aqidah menjadi bagian utama yang diintegrasikan oleh semua guru madrasah dalam kegiatan pembelajaran. Untuk menanamkan nilai akidah, guru selalu mengaitkan materi yang diajarkan dengan ayat al-Qur'an, alHadits, dan sejarah Islam. Guru mengaitkan nilai ketakwaan kepada Allah SWT dalam setiap materi yang diajarkan. Seorang guru mengungkapkan:

"Saya mengaitkan materi pembelajaran yang saya ajarkan dengan sejarah Islam tentang matematika. Hal ini saya lakukan agar para siswa lebih mengenal kekuasaan Allah sehingga imannya meningkat dan kecintaan terhadap pengetahuan menguat." (6).

Materi yang diajarkan oleh guru setiap bidang studi di madrasah ini dilakukan dengan mengaitkannya dengan sejarah Islam dengan tujuan agar peserta didik memahami dan memaknai bahwa Islam harus masuk dalam dirinya. Mempelajari Islam dengan baik sehingga memiliki sifat cerdas dan pengetahuan yang luas. Seorang guru Akidah Akhlak mengungkapkan bahwa:

"Kebijakan Kepala Madrasah mewajibkan kami semua guru yang ada di Madrasah ini mengaitkan nilainilai Islam dalam setiap pembelajaran di kelas maupun di luar kelas. Ini juga tidak hanya untuk guru mata pelajaran rumpun keislaman, tapi juga untuk semua guru yang mengajar tak terkecuali guru mata pelajaran nonkeagamaan. Saya pun telah melakukan hal ini dalam beberapa tahun belakangan dan tentu menuntut saya dan semua guru untuk mempelajari Islam lebih luas. Dampaknya, peserta didik terihat lebih Islami dan mengembangkan diri lebih bijaksana dalam berbicara dan bertindak. Islam selalu kami kedepankan di Madrasah ini." (7).

Di sini tergambar bahwa nilai-nilai Islam dikembangkan dalam proses pembelajaran dengan tujuan agar peserta didik memiliki perilaku mencintai ilmu pengetahuan dan bijaksana dalam bertindak. Peserta didik memiliki motivasi tinggi dalam belajar serta mengembangkan sikap mencintai ilmu pengetahun. Anjuran guru menjadi hal selalalu diingat dan dikembangkan oleh peserta didik dalam tindakan pembelajaran baik di linkungan madrasah maupun di rumah. "Peserta didik lebih mudah diatur, kecintaan untuk belajar meningkat, dan mereka gemar membaca buku," (2).

Temuan penelitian ini diperkuat oleh penelitian yang dikemukakan oleh 
Muspiroh (2014) bahwa nilai-nilai Islam mesti diintegrasikan oleh guru manapun di madrasah dalam pengembangan wasasan materi pembelajaran yang diajarkan. Penelitian Hakim (2012) mendukung temuan penelitian ini bahwa internalisasi nilai Islami dilaksanakan dengan penjelasan wawasan materi dan mengaitkannya dengan nilai Islam yang bersumber dari ajaran Islam. Hal ini berdampak pada paradigma siswa dan perilaku mereka lebih Islami. Penelitian lain mengungkapkan bahwa proses internalisasi dilakukan dengan mengaitkan materi pembelajaran dengan perilaku kebaikan manusia, yaitu akhlak pada Allah, manusia, lingkungan dan orang tua (bin Abdul, 2016; Usman \& Widyanto, 2019; Tambak, et al., 2018). Aspek nilai-nilai agama Islam yang diinternalisasikan dalam pembelajaran melahirkan perilaku: kecintaan kepada al-Qur'an, mencintai ilmu, berpikir tingkat tinggi, menghargai karya orang lain, dan beradab (Tambak, Ahmad, and Sukenti, 2020; Bermi, 2016). Di sinilah daya jiwa mufakkara mesti dididik agar melahirkan perlaku bajik sehingga mampu menghantar diri manusia menembus keagungan Allah SWT.

\section{PENUTUP}

Berdasarkan hasil uraian sebelumnya maka dapat dikemukakan temuan penelitian yaitu: Pertama, membiasakan shalat dhuha, dan shalat fardhu berjamaah, untuk mengelola daya jiwa syahwiya peserta didik, menghasilkan akhlak Islami "iffah" yang kemudian melahirkan akhlak lainnya yaitu jud, syakha', qana'ah, amanah, zuhud, rahmah, hilm, dan al-afwu. Kedua, membiasakan shiyam sunnah, dan tahfiz al-Qur'an, untuk mengekang daya jiwa hammiya peserta didik, sehingga menghasilkan akhlak Islami "syaja'ah" dan melahirkan "adalah" yang kemudian melahirkan akhlak lainnya yaitu ihsan, insyaf, rahmah, dan hilm. Ketiga, membiasakan kegiatan muhadharah, dan internalisasi nilai Islam dalam pembelajaran, untuk mendidik daya jiwa mufakkara peserta didik, sehingga melahirkan perilaku "hikmah" yang kemudian melahirkan akhlak Islami "fathanah". Mengembangkan ketiga hal ini kemudian melahirkan akhlak lainnya yaitu jud, hilm, mujahadah, dan sabr pada diri siswa dalam kehidupan sehari-hari. Maka berdasarkan hal demikian dapat disimpulkan dimana proses penginternalisasian nilai Islami untuk mengembangkan akhlak aktual siswa adalah dengan membiasakan shalat dhuha, shalat fardhu berjamaah, membiasakan shiyam sunnah, tahfiz alQur'an, membiasakan kegiatan muhadharah, dan internalisasi nilai Islam dalam pembelajaran, untuk mengekang daya jiwa syahwiya, mengelola daya jiwa hammiya, dan mendidik daya jiwa mufakkara peserta didik, sehingga melahirkan akhlak Islami 'iffah, jud, syakha', qana'ah, amanah, zuhud, rahmah, hilm, al-afwu, syaja'ah, 'adalah, ihsan, insyaf, mujahadah, sabr, hikmah, fathanah, dan insyaf. Maka diharapkan hasil penelitian ini diterapkan oleh Kantor Kementerian Agama Kota Pekanbaru untuk mengembangkan akhlak siswa di madrasah. Di samping itu diskusi intensif dan penelitian tentang pengembangan akhlak pada lokasi yang lebih luas sampai perguruan tinggi, dengan penelitian eksperiman maupun pengembangan. []

\section{DAFTAR RUJUKAN}

al-Isfahani, al-Isfahani. al-Dhari'a ila Makarim al-Syari'ah. Abu Yazid al"Ajmy (ed.). Kairo: Dar al-Wafa', 1987.

Amri, Rido. Dampak pembiasaan Shalat Dhuha terhadap Akhlak Karimah Siswa di SMK Plus Al-Ghifari Bandung. Diss. UIN Sunan Gunung Djati Bandung, 2018.

Amril. Akhlak Tasawuf: Meretas Jalan Menuju Akhlak Mulia. Bandung: 
Refika Aditama, 2015.

Amril. Etika Islam: Telaah Pemikiran Filsafat Moral Raghib al-Isfahani. Yogyakarta: Pustaka Pelajar Bekerjasama dengan LSFK2P, 2002.

Asyifa, Atinal. Pembiasaan Berpuasa Sunnah di Kalangan Santri Pondok Pesantren Putri Ath-Thohiriyyah Parakanonje Karangsalam Kidul Kedungbanteng Banyumas. Diss. IAIN Purwokerto, 2019.

Avivah, Nur. Pengaruh Zikir dan Shalat Fardhu Berjamaah terhadap Spiritual Quotient Santri di Pondok Pesantren Al-Barokah Mangunsuman Siman Ponorogo. Diss. IAIN Ponorogo, 2020.

Ayu, Sovia Mas, and Junaidah Junaidah. "Pengembangan Akhlak pada Pendidikan Anak Usia Dini." AlIdarah: Jurnal Kependidikan Islam 8.2 (2018): 210-221.

Ayunda, Anisa Putri. Penanaman Nilai Akhlak Melalui Pembiasaan Shalat Dhuha Di SD IT Harapan Bunda Purwokerto. Diss. IAIN, 2019.

Basuki, Danang Dwi, and Hari Febriansyah. "Pembentukan Karakter Islami melalui Pengembangan Mata Pelajaran Akidah Akhlak di Madrasah Aliyah An-Najah Bekasi." Jurnal Intelektual: Jurnal Pendidikan dan Studi Keislaman 10.2 (2020): 121-132.

Bermi, Wibawati. "Internalisasi Nilai-Nilai Agama Islam untuk Membentuk Sikap dan Perilaku Siswa Sekolah Dasar Islam Terpadu Al-Mukminun Ngrambe Ngawi." AL-LUBAB: Jurnal Penelitian Pendidikan dan Keagamaan Islam 2.1 (2016): 1-18.

bin Abdul Rashid, Muhammad Shawal, and Tengku Aisha Tengku Mohd Azman. "Predicting the intention to cyberbully and cyberbullying behaviour among the undergraduate students at the International Islamic University Malaysia." International Journal of
Education 2.5 (2017): 257-270.

Budianto, Ahmad. "Implementasi Shalat Dhuhur Berjamaah untuk Membentuk Akhlak Siswa di Madrasah Aliyah Negeri 2 Pamekasan." Rabbani: Jurnal Pendidikan Agama Islam 1.1 (2020): 11-26.

Chen, Wei-Lin, and Yun-Wen Chan. "Can higher education increase students' moral reasoning? The role of student engagement in the US." Journal of Moral Education (2020): 1-17.

Dian, Wahyu Binti Nurohmah. Peran Guru dalam Meningkatkan Percaya Diri Siswa Melalui Kegiatan Ekstrakurikuler Muhadharah di Mi Ma'arif Al-Ishlah Kalisat Bungkal Ponorogo. Diss. IAIN Ponorogo, 2018.

Firdaus, Rizki. Implikasi Shalat Sunah Dhuha pada Akhlak Siswa: Penelitian di Madrasah Aliyah Negeri 02 Kota Bandung. Diss. UIN Sunan Gunung Djati Bandung, 2019.

Ganjvar, Mahdi. "Islamic Model of Children's Spiritual Education (CSE); its influence on improvement of communicational behaviour with non-coreligionists." International Journal of Children's Spirituality 24.2 (2019): 124-139.

Haibah, Mujahidatul, et al. "Pembiasaan Membentuk Karaktek Peserta Didik Madrasah Miftahul Huda Musi Rawas Utara." Jurnal Pendidikan Agama Islam Al-Thariqah 5.2 (2020): 23-32.

Hakim, Lukman. "Internalisasi Nilai-Nilai Agama Islam dalam Pembentukan Sikap dan Perilaku Siswa Sekolah Dasar Islam Terpadu Al-Muttaqin Kota Tasikmalaya." Jurnal Pendidikan Agama Islam Ta'lim 10.1 (2012): 67-77.

Hartini, Nyimas. Pengaruh Kedisiplinan Salat dan Pembiasaan Puasa Sunah terhadap Akhlak Peserta Didik di 
MTs Al Mubaarak Kota Bengkulu. Diss. IAIN Bengkulu, 2015.

Husna, Asmaul. Pembiasaan Puasa Sunat dan Korelasinya dalam Membentuk Karakter Anak. Diss. UIN Ar-Raniry Banda Aceh, 2016.

Ibnu Miskawaih, Abi 'Ali Ahmad bin Muhammad bin Ya'kub. Tahzib alAkhlak; Dirasatu wa Tahqiq 'Imad alHilali. Bairut-Libanon: Jami' Huquq al-Thab'i wa al-Nayr wa al-Iqtibas bi al-Lughat al-Arabiyah Mahfuzat Limansyurat al-Jamal, 2011.

Ibrahim, Anwar, Muhammad Sarbini, and Ali Maulida. "Implementasi Metode Pembiasaan Shalat Tahajud dan Puasa Senin-Kamis pada Pembentukan Akhlak Karimah di Sekolah Unggulan Islami Leuwiliang Bogor." Prosa PAI: Prosiding Al Hidayah Pendidikan Agama Islam 1.2B (2019): 130-143.

Ikhsan, Muhammad. Pembinaan Pelaksanaan Shalat Fardhu Berjamaah bagi Siswa SMAN 2 Unggul Ali Hasjmy di Aceh Besar. Diss. UIN Ar-Raniry Banda Aceh, 2017.

Karim, Abdul. Implementasi pembelajaran akidah akhlak dalam pengembangan kepribadian siswa di MTs PAB 2 Sampali. Diss. Universitas Islam Negeri Sumatera Utara, 2017.

Karjanto, Yusup. "Signifikasi Shalat Berjamaah Terhadap Kedisiplinan Siswa Di Madrasah Aliyah An-Nafiah Banjaran Baureno Bojonegoro." EDU-RELIGIA: Jurnal Keagamaan dan Pembelajarannya 1.1 (2018): 36-48.

Khoirum, Umi. Muhadharah sebagai Training Public Speaking di Pondok Pesantren Pancasila Kota Bengkulu. Diss. IAIN BENGKULU, 2019.

Kurnia, Agnes Rizki. Strategi Pelatihan Muhadharah Pondok Pesantren Darel Hikmah Pekanbaru Dalam Meningkatkan Kemampuan Dakwahbi Al-Lisan Santriputra. Diss.
Universitas Islam Negeri Sultan Syarif Kasim Riau, 2018.

Laeheem, K. "Islamic Background of Thai Muslim Youth with Islamic Ethical Behaviour: A study of Muslim Youth in Three Southern Border Provinces of Thailand." Journal of Social Sciences \& Humanities (2017): 1625.

Laila, Zahrah Nurnajmi. Pengaruh Shalat Dhuha Terhadap Akhlak Siswa di SMP Negeri 11 Kota Bogor. BS Thesis. Jakarta: Fakultas Ilmu Tarbiyah dan Keguruan UIN Syarif Hidayatullah, 2020.

Maghfuroh, Annis. Pembiasaan Puasa Sunnah Senin Kamis pada Siswa Smp Alam Al Aqwiya Langgongsari Kecamatan Cilongok Kabupaten Banyumas. Diss. IAIN, 2019.

Mamat, Mohd Nor, and Siti Fatahiyah Mahamood. "Islamic philosophy on behaviour-based environmental attitude." Asian Journal of Environment-Behaviour Studies 2.2 (2017): 81-91.

Maulida, Ali. "Konsep dan Desain Pendidikan Akhlak dalam Islamisasi Pribadi dan Masyarakat." Edukasi Islami: Jurnal Pendidikan Islam 2.4 (2017): 414-423.

Md, Ak Mohd Aiman Pg Hj. "Personalities Development and Role of Teachers for Visual Impairment Student at Institute Tahfiz Quran Sultan Haji Hassanal Bolkiah." Journal of Quran Sunnah Education \& Special Needs 4.1 (2020): 28-41.

Merriam, Sharan B. Qualitative Research and Case Study Applications in Education. San Francisco: JosseyBass Publishers, 1998.

Miles, Matthew B, and A. Michael Huberman. Qualitative Data Analysis:An Expanded Sourcebook. Thousand Oaks.: Sage, 1994.

Mohamed, Sofiah, Kamarul Azmi Jasmi, and Muhammad Azhar Zailaini. "Akhlak Guru dalam Pengajaran dan Pembelajaran Pendidikan Islam." 
Akademika 86.2 (2016): 292-311.

Mu'awanah, Elfi. "Psychology Counseling of Sufistic Method for an EXHoodlum and Prostitute to Be Islamic Behaviour Shift (Quran Memorizers)." Psychology Research 8.11 (2018): 558-566.

Muspiroh, Novianti. "Integrasi nilai-nilai islam dalam pembelajaran IPA di sekolah." Quality 2.1 (2014): 168188.

Ningsih, Wiji Astuti. Pendidikan karakter religius melalui pembiasaan shalat dzuhur berjamaah kelas $V$ di $S D$ Islam Al-Madina Kota Semarang tahun 2016/2017. Diss. UIN Walisongo, 2017.

Nurani, Nira. "Implementasi Pembentukan Akhlak Terpuji Melalui Pembiasaan Shalat Dhuha pada Kelompok B Usia 5-6 Tahun TK Islam An Nuur Tahun Ajaran 2018-2019." Utile: Jurnal Kependidikan 5.2 (2019): 98-103.

Patton, Michael Quinn. Qualitative Evaluation and Research Methods. London: Sage Publications, 2002.

Rosad, Wahyu Sabilar. "Pelaksanaan Shalat Dhuha dalam Meningkatkan Kecerdasan Spiritual Siswa Kelas 3 Madrasah Ibtidaiyah Ma'arif $\mathrm{Nu}$ Ajibarang Wetan." Al-Muqkidz: Jurnal Kajian Keislaman 8. 1 (2020): 23-42.

Saani, Kholilur Rohman. Pengaruh Pembiasaan Shalat Fardhu Lima Waktu Berjamaah dalam Mencegah Kenakalan Santri Di Pondok Pesantren Manbaul Hikam Putat Tanggulangin Sidoarjo. Diss. UIN Sunan Ampel Surabaya, 2017.

Sapitri, Indah Suci. "Hubungan Pembiasaan Shalat Dhuha Dengan Akhlak Siswa Sekolah Menengah Atas." Jurnal Pendidikan Islam Indonesia 5. 1 (2020): 31-48, doi:10.35316/jpii.v5i1.246.

Seidman, I. E. Interviewing as a Qualitative Research: A Guide for Researches in
Education and the Social Sciences. New York: Teachers College, Columbia Unversity, 1991.

Strauss, A. \& J. Corbin. Basic Qualitatif Research: Grounded theory Procedures and Techniques. Newbury Park: Sage Publication, 1990.

Sulistiawati, Nengsih. Muhadharah Sebagai Latihan Pengembangan Kemampuan Berbicara Siswa (Studi di Madrasah Tsanawiyah Negeri 3 Lebak). Diss. Universitas Islam Negeri" Sultan Maulana Hasanuddin" BANTEN, 2017.

Tambak, Syahraini and Desi Sukenti. "Strengthening Islamic Behavior and Islamic Psychosocial in Developing Professional Madrasah Teachers." Cakrwala Pendidikan: Jurnal Ilmiah Pendidikan 39.1 (2020): 65-78.

Tambak, Syahraini, and Desi Sukenti. "Pengembangan Profesionalisme Guru Madrasah Dengan Penguatan Konsep Khalifah." Hayula: Indonesian Journal of Multidisciplinary Islamic Studies 4.1 (2020): 41-66.

Tambak, Syahraini, et al. "Development of Madrasah Teacher Professionalism by Strengthening the Khalifah Concept and Islamic Psychosocial Perspective." International Conference on Islamic Education (ICIE 2018). Atlantis Press, 2018.

Tambak, Syahraini, M. Yusuf Ahmad, and Desi Sukenti. "Strengthening Emotional Intelligence in Developing the Madrasah Teachers' Professionalism." Akademika:

Journal of Southeast Asia Social Sciences and Humanities 90.2 (2020): 27-38.

Tambak, Syahraini. "Pendidikan Etika Bergaul Islami Dalam Keluarga" Nilai Pendidikan Etika Berlaku Adil Orangtua dengan Anak dalam Pergaulan Keluarga Perspektif 
Hadits"." Jurnal Pendidikan Agama Islam Al-Thariqah 4.1 (2019): 1-20.

Usman, Muhammad, and Anton Widyanto. "Internalisasi Nilai-Nilai Toleransi dalam Pembelajaran Pendidikan Agama Islam di SMA Negeri 1 Lhokseumawe." DAYAH: Journal of Islamic Education 2.1 (2019): 36-52.

Vojdani, Fatemeh, and Kavoos Roohi Barandagh. "Respect for Others from Attitude to Behaviour an Islamic View." European Journal of Science and Theology 14.4 (2018): 151-164.

Warasto, Hestu Nugroho. "Pembentukan Akhlak Siswa." Jurnal Mandiri: Ilmu Pengetahuan, Seni, dan Teknologi 2.1 (2018): 65-86.

Zahara, Aulia. Pelaksanaan Kegiatan Muhadharah sebagai Upaya Meningkatkan Percaya Diri Santri di Pondok Pesantren Al-Qur'an Harsallakum Kota Bengkulu. Diss. IAIN BENGKULU, 2020.

Zainuddin, Zainuddin. "Pengembangan Buku Ajar Akidah Akhlak untuk Meningkatkan Pemahaman Siswa Madrasah." Jurnal Pendidikan Islam Indonesia 3.2 (2019): 216-229.

Zuhdi, Muhammad, Pembinaan Akhlak Siswa Melalui Shalat Dhuha di SMP Muhammadiyah 1 Karanglewas Kabupaten Banyumas. Diss. IAIN, 2019. 